\title{
Chemotherapeutic alteration of $\beta$-catenin and c-kit expression by imatinib in p16-positive squamous cell carcinoma compared to HPV-negative HNSCC cells in vitro
}

\author{
J.D. SCHULTZ ${ }^{1}$, J.U. SOMMER ${ }^{1}$, S. HOEDT ${ }^{1}$, P. ERBEN ${ }^{2}$, R.D. HOFHEINZ ${ }^{2}$, \\ A. FABER ${ }^{1}$, C. THORN ${ }^{1}$, K. HÖRMANN ${ }^{1}$ and A. SAUTER ${ }^{1}$ \\ ${ }^{1}$ Department of Otorhinolaryngology, Head and Neck Surgery, and ${ }^{2}$ Department of Hematology and \\ Oncology, Medical Faculty of Mannheim, University of Heidelberg, Mannheim, Germany
}

Received July 10, 2011; Accepted September 1, 2011

DOI: 10.3892/or.2011.1499

\begin{abstract}
The most common neoplasm arising in the upper aerodigestive tract is head and neck squamous cell carcinoma (HNSCC). Tumor growth, invasion and systemic dissemination is a multistep process of dysregulated cellular signaling pathways and an altered cell-cell and cell-matrix interaction. Aberrant $\mathrm{Wnt} / \beta$-catenin signaling is linked to tumor development and dissemination in several tumor entities. $\beta$-catenin is a multifunctional protein within the canonical Wnt pathway, which is an important factor for reducing cell-cell adhesion in malignant tissue and for triggering cell cycle progression and unscheduled proliferation. Another pivotal factor in carcinogenesis is the tyrosine kinase receptor c-kit, which in the case of dysregulated expression is associated with neoplastic transformation in epithelial tissue. This study evaluates the expression pattern of secreted and nuclear $\beta$-catenin and c-kit in p16-positive and HPV-negative squamous cell carcinomas
\end{abstract}

Correspondence to: Dr J.D. Schultz, University HNO-Klinik, Universitaetsmedizin Mannheim, Theodor Kutzer Ufer 1-3, D-68167 Mannheim, Germany

E-mail: johannes.schultz@umm.de

\begin{abstract}
Abbreviations: abl, Abelson murine leukemia viral oncogene homolog; APC, adenomatosis polyposis coli; CML, chronic myeloid leukemia; DNA, deoxyribonucleic acid; ECM, extracellular matrix; ELISA, enzyme-linked immunosorbent assay; ErbB-2, human epidermal growth factor receptor 2; Fz-receptor, frizzled receptor; GSK-3 $\beta$, glycogen synthase kinase $3 \beta$; HNSCC, head and neck squamous cell carcinoma; MMP-7, matrix metalloproteinase-7; NSCLC, non-small cell lung carcinoma; p53, tumor protein 53; PBS, phosphate-buffered saline; PTKs, protein tyrosine kinase; SCC, squamous cell carcinoma; SDS-PAGE, sodium dodecylsulphate polyacrylamide gel electrophoresis; Siah-1, seven in absentia homolog; E3, ubiquitin-protein ligase; TGF, transforming growth factor; Wnt, wingless hybrid of Int and $\mathrm{Wg}$ (wingless) and Int1 (integration 1)
\end{abstract}

Key words: imatinib, $\beta$-catenin, c-kit, head and neck squamous cell carcinoma, protein tyrosine kinase, human papillomavirus
(SCC) and the vulnerability of therapy with the tyrosine kinase inhibitor imatinib as a potential targeted treatment modality compared to platinum-based chemotherapeutic drugs. The different squamous tumor cell lines were incubated with increasing concentrations of carboplatin ( 3 or $7.5 \mu \mathrm{mol} / \mathrm{ml})$ and imatinib (18 or $30 \mu \mathrm{mol} / \mathrm{ml})$. ELISA and immunohistochemical methods were carried out after 48, 72, 120, 192 and $240 \mathrm{~h}$. We detected a reliable trend towards significantly decreased cytosolic and nuclear $\beta$-catenin and c-kit expression levels in p16-positive SCC and non-HPV HNSCC cells induced by imatinib exposure for an extended incubation period, whereas platinum-based agents had no or, at best, a slight influence. Virus-transformed squamous cell carcinoma (CERV196) cells were characterized by a reduced susceptibility to an imatinibaltered $\beta$-catenin expression. Further studies are planned to investigate this observance in HPV-positive HNSCC in vitro. The implementation of a selective molecular therapy in established chemotherapeutic regimes may enhance the efficacy of platinum-based chemotherapy without increased toxicity and could thus improve the clinical outcome in HNSCC, irrespective of the HPV status.

\section{Introduction}

With a global annual incidence of $\sim 644,000$ cases and 352,000 associated deaths, head and neck squamous cell carcinoma (HNSCC) is the fifth most common cancer worldwide $(1,2)$. HNSCC is a heterogeneous group, consisting of various tumor entities, which differ greatly in tumor aggressiveness and response to treatment. HNSCC is characterized by local invasiveness and a propensity for dissemination to cervical lymph nodes and systemic metastasis. The poor five-year survival rate has remained unchanged in the last decades despite improved techniques in diagnostics and treatment modalities in surgery, radiation and chemotherapy (3). Therefore, it is urgently necessary to identify new molecular determinants in order to develop innovative therapeutic approaches in HNSCC.

Recently there has been increasing awareness about a subset of squamous cell carcinomas (SCCs) induced by oncogenic forms of the human papilloma virus (HPV) (highrisk types 16 and 18). Not only molecular pathology but also 
epidemiological studies proved the causal association between HPV16 and a subset of oropharyngeal cancers. Furthermore, this viral etiology seems to be linked to specific subtypes of HPV-associated HNSCC like HPV 16 and 18, especially to those arising from the tonsils and the tongue base. In contrast to the overall falling incidence of head and neck cancers in the USA in recent years, the incidence of HPV-associated oropharyngeal cancer is rising, indicating the increased importance of elucidating the viral etiology (4-7). High-risk HPV infection has been associated with anogenital carcinomas, including cervical, anal, vulvar and penile cancers, and more recently, breast cancer (7). Augmented incidence of HPV-associated oropharyngeal cancers represents an emerging viral epidemic. HPV-positive HNSCC may be responsible for oropharyngeal cancer and seems to be different from tobacco- and alcoholinduced HNSCC (non-HPV) in its genetic, molecular and clinical profile. In the USA, 40-80\% of oropharyngeal cancers are associated with HPV, whereas in Europe data are heterogeneous and vary from $20 \%$ in countries with high tobacco and alcohol consumption, such as Russia, to $90 \%$ in countries with low tobacco and alcohol consumption, such as Sweden. This implies that HPV is now the primary cause of tonsillar carcinoma in North America and Europe (8-11).

Based on their capacity to persist in basal mucosa cells, the family of Papillomaviridae, consisting of at least 200 genotypes could be classified in low- and high-risk types (11). Due to the above-mentioned capacity, the infected cells avoid the clearance by the immune system, and evolve their potential for transformation by expression of viral oncogenes. Typical sites of HPV infection are the basal layer or the stratified squamous epithelium through structural breaks or microabrasions in the skin and mucosa surfaces (12). Evading the host immune system by residing in the basal epithelium, HPV-infected cells depict viral oncogenes, which suppress pro-inflammatory signaling (13).

The expression of the E6 and E7 oncogenes and the loss of function of several key regulatory proteins affect cell cycle progression, proliferation and de-differentiation of the infected mucosa cells and thereby prove to be indispensable for the induction and maintenance of the transformed phenotype $(14,15)$. In consequence, the genetic instability increases by integration of its viral DNA into the host genome, leading to dysregulated expression of E6 and E7 $(15,16)$. Furthermore, E6 and E7 oncoproteins are able to immortalize primary keratinocytes from the upper respiratory tract epithelium and to alter cell cycle regulatory pathways in $\operatorname{HNSCC}(17,18)$. Various studies have proven the ability of E6 and E7 in participating in the control of genome stability or in the regulation of signaling pathways that involve cell-cell interactions and cytoskeleton organization (19). The unconstrained expression of the aforementioned viral oncoproteins perturbs cell differentiation, tissue architecture and enhances cell cycle progression $(15,16)$. Tumor growth, angiogenesis and invasion is a multistep process of dysregulated cellular signaling pathways, uncontrolled cell proliferation and an altered cell-cell and cell-matrix interaction with degradation of ECM (extracellular matrix) and intercellular junctions. Epithelial tumor cells migrate by overcoming adherent cell-cell contact and invade through the basement membrane and stroma. In HNSCC, invasion of tumor cells and extension into the underlying tissues is a precondition for the development of metastasis to regional lymph nodes and distant sites, which adversely affect patient survival (20).

During the development of complex organisms, various cell surface receptors and ligands facilitate tissue pattern formation and cellular differentiation (21). The expression of these receptors and ligands is often no longer required in fully matured adult tissues. Thus, the impact of these cascades on cellular de-differentation and tissue patterning, is of special interest if activated unconstrained. Genes of the wingless (Wnt) and frizzled (Fz) class have an established role in cell morphogenesis, cellular differentiation and morphologic patterning (22). One crucial cellular signaling cascade is the Wnt/ $\beta$-catenin pathway, the aberrant activation of which has been linked to tumor development and dissemination, in several tumor entities (23-27). $\beta$-catenin is a multifunctional protein within the Wnt-pathway, which is considered to be one of the most important factors for reducing cell-cell adhesion in malignant tissues (28). $\beta$-catenin serves as a component of the cytoskeleton in a multiprotein complex linked to an epithelial adhesion molecule of the cadherin protein family (29). $\beta$-catenin/E-cadherin association is critically important for the maintenance of tight cell-cell adhesion and thus tissue architecture. Loss of cell adhesion and transformation in a mesenchymal phenotype, described as epithelial mesenchymal transition (EMT) is one fundamental step inducing invasion and progression $(30,31)$.

As a nuclear downstream effector of the canonical Wnt-signaling cascade, $\beta$-catenin plays a crucial role in the development of head and neck cancer $(32,33)$. Reduced assembly of membranous $\beta$-catenin, through destabilization of cell-cell adhesion, or alteration of the degradation complex, induces the accumulation of cytoplasmic $\beta$-catenin leading to its nuclear translocation. As a co-activator for the LEF/ TCF transcription factor, $\beta$-catenin activates target genes like cyclin D1, c-myc, matrix metalloproteinase-9 (MMP-9) and other oncogenes resulting in dysregulation of cell-cycle progression and unscheduled proliferation (33-36). In normal tissue in the absence of Wnt-ligands, cytosolic $\beta$-catenin is rapidly phosphorylated at multiple serine and threonine sites near the $\mathrm{NH}_{2}$-terminal region of the protein by the catenin destruction complex. A multiprotein complex including adenomatosis polyposis coli (APC), glycogen synthase kinase $3 \beta$ (GSK-3 $\beta$ ) and axin/conductin, facilitates phosphorylation and proteasomal degradation of $\beta$-catenin, thereby sequestering a major fraction of the pool of $\beta$-catenin protein and ensuring low cytosolic concentrations $(37,38)$. In various types of cancer, mutations in key phosphorylation sites in the $\mathrm{NH}_{2}$-terminal region of $\beta$-catenin confer resistance to ubiquitination and subsequent degradation, thereby increasing the amount of free/cytosolic $\beta$-catenin available for nuclear translocation (39).

Protein tyrosine kinase receptors (PTKs) are essential elements of the intracellular signal transduction pathway that regulates cell growth, development and apoptosis (40). Disruption of regulated PTK activity has been observed in various cancers. Constitutively active PTKs often perturb the normal cell signaling pathway and might lead to malignant transformation (41). The superfamily of transmembrane receptor proteins is activated by binding of the corresponding ligand, such as the epidermal growth factor (EGF), vascular 
endothelial growth factor (VEGF), platelet-derived growth factor (PDGF) or the transforming growth factor (TGF), to the tyrosine kinase domain of the receptor. Second messenger molecules provide downstream signals that enhance cell survival and increase cell proliferation (41). Targeted molecular therapy is a promising new development in treating human cancers. Unlike standard cytotoxic therapies that generally lack specificity for tumor cells and possesses various toxic side-effects, the targeted molecular approach exploits known molecular changes in neoplastic cells.

c-kit is as member of the receptor tyrosine kinase family and is structurally related to the PDGF receptor. Stem cell factor (SCF) is the pleiotropic ligand for the tyrosine kinase receptor, c-kit (42). The SCF-c-kit interaction leads to distinct biological cell responses by initiating signaling cascades involving the phophatidylinositol-3 (PI-3, kinase/Akt and RAS-mitogen-activated protein (MAP) kinase pathways $(43,44)$. The coordinated interplay of SCF and c-kit is of fundamental importance for recruitment of progenitor cells and cell differentiation in various biologic systems (45).

Various studies have observed the association between ectopic or dysregulated expression of c-kit and neoplastic transformation primarily in epithelial tissue (46-48). Ongkeko et al first reported the significantly increased expression of c-kit in HNSCC compared to benign samples (49). The expression patterns vary depending on the tumor site. Pharyngeal HNSCC showed extended c-kit expression compared to malignancies of the larynx. The majority ( $>90 \%$ ) of adenoid cystic adenocarcinomas of the head and neck were described as c-kit positive (49). A down-regulation of c-kit and a growth inhibitory effect could be demonstrated in adenoid cystic carcinomas treated with imatinib (50).

The tyrosine kinase inhibitor imatinib (STI571, Gleevec ${ }^{\circledR}$ ), Novartis, Basel, Switzerland), is a small molecular agent of the 2-phenylaminopyrimidine class and furthermore a potent inhibitor of bcr-abl, c-kit and of the PGDF receptor. It was initially applied in the treatment of chronic myeloid leukemia (CML) (51-54). The ability of imatinib to target specific tyrosine kinases, which are involved in tumorigenesis and metastasis, makes it an excellent therapeutic agent with few toxic side effects. This therapeutic option of TKI (tyrosine kinase inhibitor) is currently used in a limited number of solid cancers like gastrointestinal stromal tumors, melanomas and various forms of lung cancers (55-57). Prior studies illustrated the potential synergistic effects of the combined therapy with imatinib and cisplatin in HNSCC, regulating distinctively different biological targets and elevating the therapeutic impact $(58,59)$. In addition, as a single-treatment drug, imatinib proved to be effective in suppressing angiogenic peptides, like PDGF and VEGF expression in HNSCC- and p16-positive SCC.

The complexity of the Wnt-signaling pathway parallels the complexity observed in the diversity of Wnt-receptors. A vast number of receptors take part in this concerted performance of extracellular ligand and transmembrane receptor interaction. Wnt receptors include the Fz family, low density lipoprotein receptor-related proteins-5/6 (LRP-5/6) and receptor tyrosine kinase-like orphan receptor-1/2 (ROR1/2). In many analyzed receptor structures, the $\mathrm{N}$-terminus is characterized by the presence of an $\alpha$-helical, cysteine-rich domain (CRD) that interacts with Wnts and other Wnt receptors. Notably, this
CRD motif is not unique to $\mathrm{Fz}$ and Fz-type receptors. It is also found in tyrosine kinase receptors $(60,61)$.

The purpose of this study was to evaluate the expression pattern of secreted and nuclear $\beta$-catenin and c-kit in p16-positive SCC and HPV-negative squamous cell carcinoma (HNSCC) cells and the vulnerability of a tyrosine kinase inhibitory therapy dependent on the HPV status as a potential targeted treatment modality compared to established platinum-based chemotherapeutic drugs. To our knowledge, this is the first report of a chemotherapeutic study to treat HNSCC- and p16-positive SCC with imatinib as a single, active drug and the first study to compare expression patterns of effector molecules of the Wnt-pathway and c-kit expression in viral-transformed squamous epithelium.

\section{Materials and methods}

Cell lines and culture. The two different HNSCC cell lines $11 \mathrm{~A}$ and $14 \mathrm{C}$ were obtained from Dr T.E. Carey (University of Michigan, MI, USA). These cell lines originate from human HNSCC of the oropharynx and larynx. The CERV196 cell line was established from a poorly differentiated SCC of the cervix that is HPV-16 positive (CLS, Eppelheim, Germany). A CERV196 tumor was established in vitro from the xenotransplant cervix carcinoma MRI-H-196. CERV196 cells were cultured in Eagle's minimum essential medium with $2 \mathrm{mM} \mathrm{L}$-glutamine and Earle's BSS adjusted to contain $1.5 \mathrm{~g} / \mathrm{l}$ sodium bicarbonate, $0.1 \mathrm{mM}$ non-essential amino acids, $1.0 \mathrm{mM}$ sodium pyruvate and $10 \%$ fetal calf serum (FCS). Cell cultures were carried out at $37^{\circ} \mathrm{C}$ in a $5 \% \mathrm{CO}_{2}$ fully humidified atmosphere using Dulbecco's modified minimum essential medium (DMEM) (Fisher Scientific Co., Pittsburgh, PA, USA) supplemented with $10 \%$ FCS and antibiotics (Life Technologies Inc., Gainthersburg, MD, USA). Imatinib was gratefully provided by the manufacturer (Novartis). Imatinib and carboplatin were stored at $4^{\circ} \mathrm{C}$ and dissolved in sterile water at the time of use. The HNSCC cell lines were incubated with different concentrations and combinations of imatinib ( 18 or $30 \mu \mathrm{mol} / \mathrm{ml}$ ) and/or carboplatin ( 3 or $7.5 \mu \mathrm{mol} / \mathrm{ml}$ ) for $2,3,5$, and up to 8-10 days. These different drug concentrations and combinations were selected after performing the alamarBlue (AbD Serotec, Oxford, England) cell proliferation assay, quantitatively measuring proliferation of HNSCC tumor cell lines and establishing the relative cytotoxicity of the chemotherapeutic drugs used. After the defined incubation time, the supernatants were collected in sterile tubes and stored at $-20^{\circ} \mathrm{C}$ until further analysis.

Characterization of the cell lines (immunohistochemistry). Immunohistochemical analysis was performed using a monoclonal mouse anti-human antibody directed against $\beta$-catenin ( $\beta$-catenin: C19220; Transduction Laboratories, Lexington, KY, USA). Immunostaining was performed using the alkaline phosphatase-anti-alkaline phosphatase method (APAAP). HNSCC cells were cultured on glass coverslips overnight before immunohistochemistry. When confluent, cells underwent a fixation with acetone and alcohol (2:1) and were subsequently washed with PBS and pre-treated in a microwave, which required boiling for $15 \mathrm{~min}$ at $600 \mathrm{~W}$ using citrate buffer for $\beta$-catenin. The following steps were performed by an auto- 

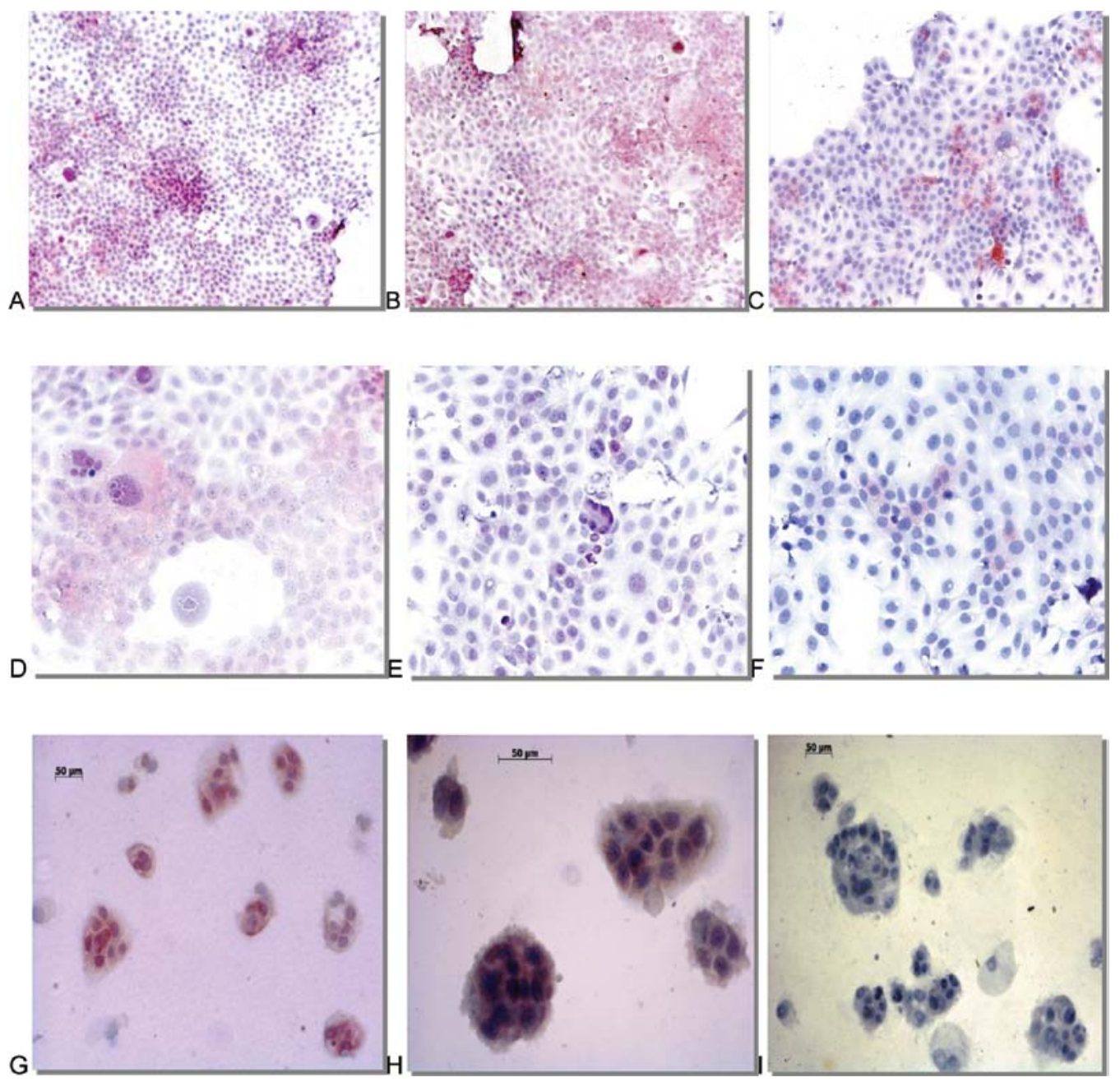

Figure 1. (A-C) Negative control and declining immunohistochemical reactivity against $\beta$-catenin after incubation with imatinib $(30 \mu \mathrm{mol} / \mathrm{ml})$ for 120 and $240 \mathrm{~h}$ (HNSCC 11A). (D-F) Negative control and declining immunohistochemical reactivity against $\beta$-catenin after incubation with imatinib (30 $\mu \mathrm{mol} / \mathrm{ml})$ for 120 and $240 \mathrm{~h}$ (HNSCC 14C). (G-I) Negative control of CERV196 with strong immunoreactivity with typical growth pattern in tumor cell colonies. Decreasing immunoreactivity was detected with a prolonged incubation period $(120$ and $240 \mathrm{~h})$ with imatinib $(30 \mu \mathrm{mol} / \mathrm{ml})$.

mated staining system, Dako TechMate 500 (Dako, Hamburg, Germany). Sections were incubated with the primary antibody solution for $25 \mathrm{~min}$ at room temperature, using a working dilution of the antibody 1:300 for $\beta$-catenin. Slides were rinsed once in buffer (Buffer kit, Dako). Immunoreaction was demonstrated with the Dako ChemMate Detection kit (APAAP, mouse, no. K5000; Dako) according to the specifications of the manufacturer. Sections were incubated with the chromogen alkaline phosphatase substrate (Neufuchsin; Dako) for $20 \mathrm{~min}$ at room temperature. Finally, sections were counterstained by Mayer's hematoxylin for $3 \mathrm{~min}$, dehydrated in graded ethanol, and a coverslip was applied. Negative controls used all reagents except the primary antibody. The results of the immunohistochemically obtained rates of expression were analysed semi-quantitatively. The staining intensity was recorded as follows: strong reactivity, $>80 \%$ of the epithelium cells were positive; moderate reactivity, $50-80 \%$ reactive; weak reactivity, $<50 \%$ reactive; and no positive cells.

$\beta$-catenin and c-kit ELISA. Cell culture supernatants were collected in sterile test tubes and stored at $-20^{\circ} \mathrm{C}$ until used. Secreted $\beta$-catenin and c-kit were measured in the supernatant of the cell lines using an ELISA technique (R\&D Systems, Wiesbaden, Germany). The system uses a solid-phase monoclonal antibody and an enzyme linked polyclonal antibody raised against $\beta$-catenin. The specificity of the anti-human $\beta$-catenin and c-kit antibodies used in the ELISA kit was examined by sodium dodecylsulphate polyacrylamide gel electrophoresis (SDS-PAGE) followed by Western blotting.

A volume of $100 \mu \mathrm{l}$ of supernatant was used for each ELISA assay. After 48, 72, 120, 192 and $240 \mathrm{~h}$ of incubation with imatinib (18 or $30 \mu \mathrm{mol} / \mathrm{ml}$ ) or carboplatin ( 3 or $7.5 \mu \mathrm{mol} / \mathrm{ml}$ ), the protein expression of $\beta$-catenin and c-kit in the supernatants of the treated and untreated culture cells was analyzed. All analyses and calibrations were carried out in duplicate. The calibrations on each microtitre plate included $\beta$-catenin and c-kit standards provided in the kit. The optical density was determined using a microplate reader at a wavelength of $450 \mathrm{~nm}$. Wavelength correction was set to $540 \mathrm{~nm}$ and concentrations were reported in $\mu \mathrm{g} / \mathrm{ml}$.

Statistical analysis. Statistical analysis was performed in cooperation with Dr C. Weiss, Institute of Biomathematics, 
Table I. ELISA for $\beta$-catenin expression in HNSCC 14C, 11A and CERV196 cells.

\begin{tabular}{|c|c|c|c|}
\hline \multirow[b]{2}{*}{ Time of incubation $(\mathrm{h})$} & \multicolumn{3}{|c|}{$\beta$-catenin expression, $\mathrm{pg} / \mathrm{ml}$ ( $\mathrm{p}$-value) } \\
\hline & Control group & Carboplatin & Imatinib \\
\hline \multicolumn{4}{|l|}{ HNSCC 11A } \\
\hline 48 & 23904 & $25288.6(0.49)$ & $19134(0.9)$ \\
\hline 72 & 23631 & $26263.6(0.2)$ & $18020(<\mathbf{0 . 0 0 1})$ \\
\hline 120 & 24206 & $24874.3(1)$ & $17886.3(<\mathbf{0 . 0 0 1})$ \\
\hline 192 & 20799.6 & $21553.3(0.1)$ & $15794.3(\mathbf{0 . 0 0 0 2})$ \\
\hline 240 & 20929.6 & $21322.3(0.8)$ & $16420.3(\mathbf{0 . 0 0 8})$ \\
\hline \multicolumn{4}{|l|}{ HNSCC 14C } \\
\hline 48 & 23892 & $21295.6(0.1)$ & $19713.3(\mathbf{0 . 0 0 0 4})$ \\
\hline 72 & 22692.6 & $21761(0.9)$ & $18127.3(\mathbf{0 . 0 0 8})$ \\
\hline 120 & 20784 & $20171(1)$ & $17442.6(0.09)$ \\
\hline 192 & 21606.3 & $19971(0.7)$ & $16515(\mathbf{0 . 0 0 2})$ \\
\hline 240 & 19801 & $18569.6(0.7)$ & $15548.6(\mathbf{0 . 0 0 1})$ \\
\hline \multicolumn{4}{|l|}{ CERV196 } \\
\hline 48 & 15861.3 & $17229.3(0.09)$ & $17927.6(0.12)$ \\
\hline 72 & 17727.6 & $17365(0.9)$ & $16286.3(0.1)$ \\
\hline 120 & 16626.3 & $16318(1)$ & $13830.3(\mathbf{0 . 0 1})$ \\
\hline 192 & 16436 & $15992.3(0.7)$ & 108678 (0.0005) \\
\hline 240 & 16962.3 & $15600.6(0.7)$ & $11870.6(\mathbf{0 . 0 0 7 5})$ \\
\hline
\end{tabular}

$\beta$-catenin (pg/ml) expression in HNSCC 11A, 14C and CERV196 cells after different periods of incubation with carboplatin (7.5 $\mu \mathrm{mol} / \mathrm{ml})$ or imatinib $(30 \mu \mathrm{mol} / \mathrm{ml})$. Mean values and statistical correlation compared to the negative control (p-value, Dunnett's test). Bold indicates statistically significant differences.

Faculty of Medicine, Mannheim. All data were subjected to the means procedure. $\mathrm{p} \leq 0.05$ was considered statistically significant. The statistical tests performed were the twocoefficient variance analysis (SAS Statistics, Cary, NC, USA) and the Dunnett's test.

\section{Results}

Immunohistochemistry for $\beta$-catenin in HNSCC 11A, $14 C$ and CERV196 cells. The results of the immunohistochemically observed rates of expression were determined semiquantitatively by two independent observers. $\beta$-catenin immunostaining was localized in the cytoplasm and nucleus of the cells (Fig. 1, Table I).

Immunohistochemical studies against $\beta$-catenin could illustrate that all tumor cell lines, irrespective of HPV status, expressed $\beta$-catenin to a similar extent. The controls showed high reactivity against secreted and nuclear $\beta$-catenin. Furthermore, a decreased reactivity of cytosolic $\beta$-catenin expression was detected, dependent on an extended incubation period with imatinib for HNSCC 11A and 14C. For CERV196, an HPV16positive carcinoma cell line, under prolonged incubation time a declining immunoreactivity against $\beta$-catenin was detectable. Exposure to a platinum-based chemotherapy had no impact on $\beta$-catenin expression and no differences in $\beta$-catenin expression patterns of negative control and tumor cell after carboplatin incubation was discernable. Increased concentrations of the treatments had no significant influence on $\beta$-catenin expression levels by immunohistochemistry.
ELISA for $\beta$-catenin expression in HNSCC 14C, 11A and CERV196 cells. $\beta$-catenin expression levels in HNSCC as well as in CERV196 tumor cells, showed a trend towards significantly decreased expression with imatinib treatment for an extended incubation period, whereas increased concentrations of the agents had no significant influence. For the purpose of simplification, only the $30-\mu \mathrm{mol} / \mathrm{ml}$ concentration of imatinib and the $7.5-\mu \mathrm{mol} / \mathrm{ml}$ concentration of carboplatin are presented and discussed in the results. Also, exposure to carboplatin had no impact on the expression of $\beta$-catenin.

For HNSCC 11A cells, there was no significant reduction of $\beta$-catenin expression levels and no evidence for a dose- or incubation period-dependent influence of the platinum-based chemotherapy when compared to the negative control. Also the effect of carboplatin, as a single active drug, in reducing cytoplasmic $\beta$-catenin expression in HNSCC 14C- and p16-positive SCC (CERV196) was negligible. Again, no dose- or incubation period-dependent effect was statistically detectable.

In contrast to treatment with carboplatin, HNSCC- and HPV16-positive CERV196 cells treated with imatinib consistently showed a significant reduction of cytoplasmic $\beta$-catenin expression levels in an incubation period-dependent manner, when compared to the negative control. The concentration had no significant influence on the expression of $\beta$-catenin. Within the time frame of $48-72 \mathrm{~h}$, there was an insignificant reduction of $\beta$-catenin expression in CERV196 cells ( $p>0.05$ ). Apparently there is a time lag until the imatinib-induced PTK inhibition has an effect on reducing $\beta$-catenin in CERV196. Whether the HPV16-positive squamous carcinoma cell line 
A

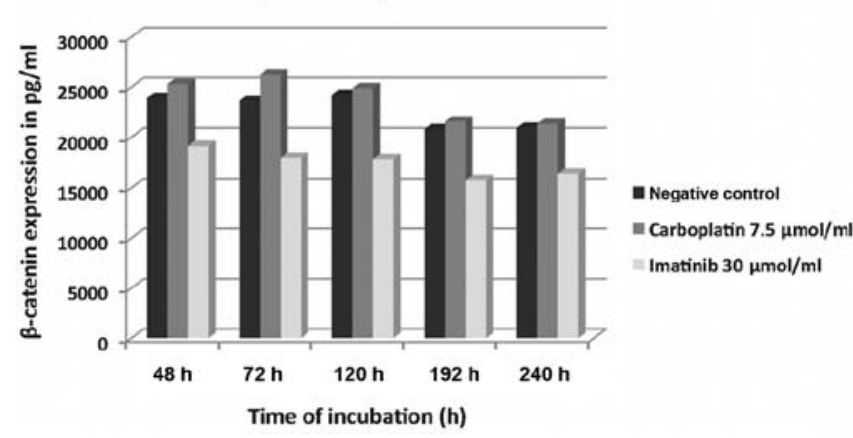

B

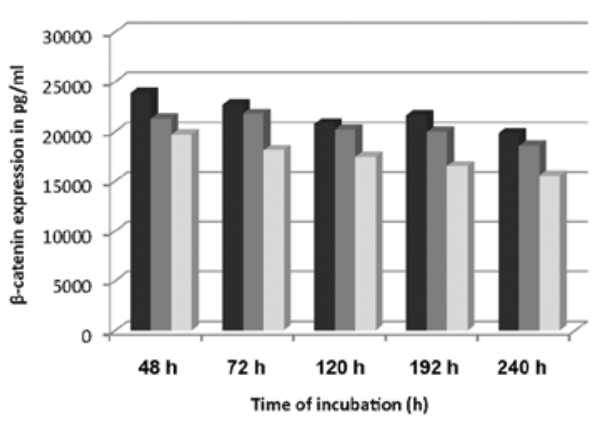

C

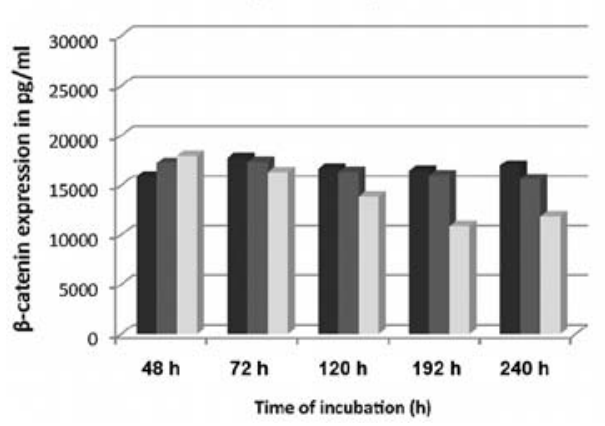

Inatinib $30 \mu \mathrm{mol} / \mathrm{ml}$

Negative control

Imatinib $30 \mu \mathrm{mol} / \mathrm{ml}$
A

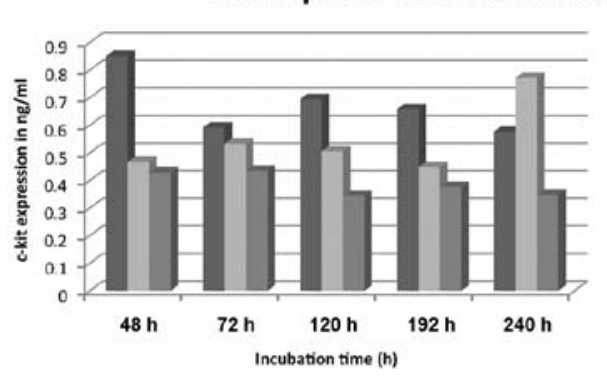

c-kit expression in HNSCC 11A

B

c-kit expression in HNSCC 14C

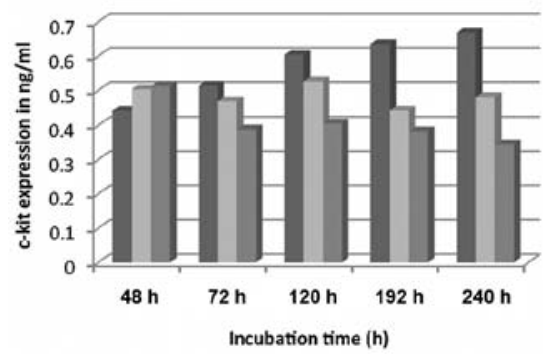

Negative control

= Carboplatin $7.5 \mu \mathrm{mol} / \mathrm{m}$

$=$ Imatinib $30 \mu \mathrm{mol} / \mathrm{ml}$

In Carboplatin $7.5 \mu \mathrm{mol} / \mathrm{ml}$

E Carboplatin 7.5 umol $/ \mathrm{ml}$

Figure 2. $\beta$-catenin expression in HNSCC 11A, 14C and CERV196 cells. $\beta$-catenin expression decreased over time (incubation periods, 48, 72, 120,192 and 240 h). Considerably lower intrinsic $\beta$-catenin expression in CERV196 cells.

is less vulnerable towards PTK therapy, particularly after short incubation periods (until $72 \mathrm{~h}$ ) remains to be assessed. Compared to non-HPV-associated tumor cell lines, negative controls of CERV196 showed lower intrinsic expression levels of secreted $\beta$-catenin. The percent suppression of secreted cytosolic $\beta$-catenin in HPV- vs. non-HPV-associated malignant tumor cells was equal (Table I). In non-HPV-associated HNSCC a consistent statistical significant suppression of cytoplasmatic $\beta$-catenin could be measured. In HNSCC $11 \mathrm{~A}$ cells a maximal reduction of $\beta$-catenin was observed after $192 \mathrm{~h}$ of imatinib treatment $\left(\mathrm{C}_{\text {imatinb192h }}=15794 \mathrm{pg} / \mathrm{ml} ; \mathrm{C}_{\text {negative_control192h }}=\right.$ $20799 \mathrm{pg} / \mathrm{ml} ; \mathrm{p}<0.002)$. In HNSCC $14 \mathrm{C}$ cells imatinib induced a time-dependent suppression of $\beta$-catenin (Table II, Fig. 2).

ELISA for c-kit expression in HNSCC 14C, 11A and CERV196. In this study we could detect a consistent trend towards significantly incubation period-dependent suppression of c-kit for non-HPV-positive HNSCC exposed to imatinib. The concentration of the treatments had no statistical significant impact

\section{C c-kit expression in CERV196}

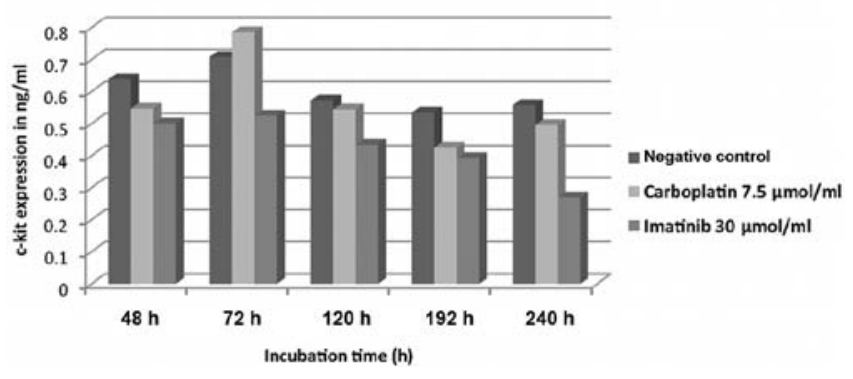

Figure 3. c-kit expression in HNSCC 11A, 14C and CERV196 cells. Decreased c-kit expression over time (incubation periods, 48, 72, 120, 192 and $240 \mathrm{~h}$ ).

on the reduction of c-kit expression levels. p16-positive SCC showed less susceptibility for the tyrosine kinase inhibitory effects of imatinib. Only after $240 \mathrm{~h}$ of incubation a statistically significant reduction of $c$-kit was notable $(p=0.006)$. Furthermore, carboplatin had no effect on the c-kit expression in CERV196 cells, neither in a dose- nor in a time-dependent manner. Compared to HPV-associated SCC, HNSCC 11A and $14 \mathrm{C}$ cells were characterized by significantly reduced c-kit levels of the supernatants with imatinib treatment. Analyzing the effect of platinum-based chemotherapy on the expression of c-kit in HNSCC, a distinct significant trend towards a suppressed c-kit expression with prolonged incubation time could be shown. Comparing the different chemotherapeutic active substances concerning the effect on a reliable decrease of the proto-oncogene, imatinib was superior to platinumbased chemotherapy (Table III, Fig. 3; statistically significant differences).

\section{Discussion}

Head and neck cancer is the sixth most common cancer worldwide. HNSCCs are marked by local invasiveness and propensity for systemic dissemination to cervical lymph nodes 
Table II. Immunoreactivity against $\beta$-catenin in HNSCC 11A, 14C and CERV196.

\begin{tabular}{|c|c|c|c|c|}
\hline Immunostaining index & $48 \mathrm{~h}$ & $72 \mathrm{~h}$ & $120 \mathrm{~h}$ & $240 \mathrm{~h}$ \\
\hline \multicolumn{5}{|l|}{ Control group } \\
\hline HNSCC 11A & $+++(3 / 3)$ & $+++(2 / 3)$ & $++(2 / 3)$ & $+++(3 / 3)$ \\
\hline HNSCC 14C & $+++(3 / 3)$ & $++(2 / 3)$ & $+++(3 / 3)$ & $+++(2 / 3)$ \\
\hline CERV196 & $++(3 / 3)$ & $++(3 / 3)$ & $+++(3 / 3)$ & $++(2 / 3)$ \\
\hline \multicolumn{5}{|l|}{ Carboplatin, $3 \mu \mathrm{mol}$} \\
\hline HNSCC 11A & $++(1 / 3)$ & $++(2 / 3)$ & $+++(2 / 3)$ & $++(1 / 3)$ \\
\hline HNSCC 14C & $++(2 / 3)$ & $+++(1 / 3)$ & $++(1 / 3)$ & $+++(2 / 3)$ \\
\hline CERV196 & $+++(2 / 3)$ & $+++(1 / 3)$ & $+++(3 / 3)$ & $+++(2 / 3)$ \\
\hline \multicolumn{5}{|l|}{ Carboplatin, $7.5 \mu \mathrm{mol}$} \\
\hline HNSCC 11A & $+++(2 / 3)$ & $++(2 / 3)$ & $++(2 / 3)$ & $++(2 / 3)$ \\
\hline HNSCC14C & $++(2 / 3)$ & $+++(2 / 3)$ & $++(1 / 3)$ & $+++(1 / 3)$ \\
\hline CERV196 & $+++(3 / 3)$ & $+++(3 / 3)$ & $+++(2 / 3)$ & $+++(2 / 3)$ \\
\hline \multicolumn{5}{|l|}{ Imatinib, $18 \mu \mathrm{mol}$} \\
\hline HNSCC 11A & $++(2 / 3)$ & $+(2 / 3)$ & $+(1 / 3)$ & $+(1 / 3)$ \\
\hline HNSCC 14C & $++(1 / 3)$ & $++(1 / 3)$ & $++(1 / 3)$ & $++(2 / 3)$ \\
\hline CERV196 & $+++(3 / 3)$ & & $++(1 / 3)$ & $++(2 / 3)$ \\
\hline \multicolumn{5}{|l|}{ Imatinib, $30 \mu \mathrm{mol}$} \\
\hline HNSCC 11A & $++(2 / 3)$ & $0(1 / 3)$ & $+(1 / 3)$ & $0(1 / 3)$ \\
\hline HNSCC 14C & $+(2 / 3)$ & $+(2 / 3)$ & $++(2 / 3)$ & $+(1 / 3)$ \\
\hline CERV196 & $++(2 / 3)$ & $++(1 / 3)$ & $++(2 / 3)$ & $+(1 / 3)$ \\
\hline
\end{tabular}

0 , no positive cells; + , weak immunostaining; ++ , moderate immunostaining; +++ , strong immunostaining. $(\mathrm{x} / 3)$, number of positive cell lines out of the HNSCC lines 14C, 11A and CERV 196.

Table III. c-kit expression in HNSCC 11A, 14C and CERV196 cells.

\begin{tabular}{|c|c|c|c|}
\hline \multirow[b]{2}{*}{ Time of incubation (h) } & \multicolumn{3}{|c|}{ c-kit expression, ng/ml (p-value) } \\
\hline & Control group & Carboplatin & Imatinib \\
\hline \multicolumn{4}{|l|}{ HNSCC 11A } \\
\hline 48 & 0.551 & $0.46(\mathbf{0 . 0 0 0 1})$ & $0.428(\mathbf{0 . 0 0 1})$ \\
\hline 72 & 0.591 & $0.5326(0.6)$ & $0.435(\mathbf{0 . 0 0 8})$ \\
\hline 120 & 0.6936 & $0.505(\mathbf{0 . 0 0 4})$ & $0.343(\mathbf{0 . 0 0 0 2})$ \\
\hline 192 & 0.6576 & $0.4473(\mathbf{0 . 0 1})$ & $0.3756(\mathbf{0 . 0 1})$ \\
\hline 240 & 0.57563 & $0.77113(0.6)$ & $0.347(\mathbf{0 . 0 0 2})$ \\
\hline \multicolumn{4}{|l|}{ HNSCC $14 \mathrm{C}$} \\
\hline 48 & 0.441 & $0.5036(0.4)$ & $0.513(0.8)$ \\
\hline 72 & 0.5136 & $0.4683(0.8)$ & $0.3883(\mathbf{0 . 0 0 1})$ \\
\hline 120 & 0.6043 & $0.5261(0.5)$ & $0.40586(\mathbf{0 . 0 1})$ \\
\hline 192 & 0.6346 & $0.4413(\mathbf{0 . 0 4})$ & $0.3823(\mathbf{0 . 0 0 0 8})$ \\
\hline 240 & 0.668 & $0.481(\mathbf{0 . 0 3})$ & $0.3443(\mathbf{0 . 0 0 4})$ \\
\hline \multicolumn{4}{|l|}{ CERV196 } \\
\hline 48 & 0.6383 & $0.546(0.4)$ & $0.5006(0.3)$ \\
\hline 72 & 0.70786 & $0.7846(0.6)$ & $0.5246(0.09)$ \\
\hline 120 & 0.5723 & $0.5443(0.8)$ & $0.4336(0.07)$ \\
\hline 192 & 0.5343 & $0.4253(0.7)$ & $0.3926(0.1)$ \\
\hline 240 & 0.558 & $0.496(0.4)$ & $0.2696667(\mathbf{0 . 0 0 6})$ \\
\hline
\end{tabular}


and are characterized by differences in tumor aggressiveness and response to treatment. The poor five-year survival rate has remained unchanged in the last decades even though improved techniques in surgery, radiation and chemotherapy have been established. Identification of predictive markers is urgent to optimize treatment and reduce impairment for the individual patient. In recent years oncological research placed more emphasis on a new etiological agents for the carcinogenesis of head and neck cancer. Epidemiological and molecular data demonstrated that high-risk human papillomaviruses (HPV) constitute important risk factors for the development of a subset of oropharyngeal cancers, which is distinct from non-HPV-associated HNSCC in their genetic, molecular and clinical profiles (62-64). HPV status is a profound prognostic factor for overall and progression free survival, treatment response and local tumor control. The superior outcome is independent of the nodal state, age, stage, tumor differentiation, gender and treatment modality (65). HPV-positive-SCC appears to be different from HPV-negative HNSCC in its molecular, epidemiological and clinical aspects as well as in the overall survival rate due to increased chemotherapeutic sensitivity (66-68). In multicellular organisms, the interaction between cells and the extracellular matrix (ECM) that maintain groups of cells together is mediated by adhesion molecules. These interactive processes are involved in different types of molecules that engage in the process of morphogenesis, normal growth, maintenance of tissue integrity, wound healing and cell polarity $(29,39)$.

The basic prerequisite of tumor progression and growth is unconstrained proliferation by dysregulation of cellular signaling and changes in tissue pattern by alteration of cellcell interactions. Various studies of epithelial malignancies have demonstrated that loss of sufficient cell adhesion and the acquisition of mesenchymal features, the so-called epithelialmesenchymal transition (EMT), are guarantors for invasion and systemic dissemination $(30,31)$. The E-cadherin/catenin complex plays a pivotal role in the maintenance of normal adhesion in epithelial cells, and has been demonstrated to suppress tumor invasion and participate in cell signaling in human carcinomas. The hallmark of human carcinomas is defective cell-cell and cell-matrix adhesion. A loss or decrease in E-cadherin expression is common in many human epithelial malignancies. Tumor invasion is a complex process that requires active interactions between the invading cell, the ECM and other stromal elements (69). At least three coordinated processes are necessary for invasion: changes in cell-cell and cell-matrix adhesion; degradation of the ECM; and cell migration (69).

As a functional component of the cadherin/catenin adhesion system and a nuclear effector of the canonical Wnt signaling pathway thus regulating the expression of several proto-oncogenes including c-myc, cyclin D1 and matrix metalloproteinase-7 (MMP-7), the cytoplasmic $\beta$-catenin pool, which possesses tumorigenic behavior demands strict regulation. For the establishment and maintenance of the malignant phenotype the expression of viral oncogenes E6 and E7 are pivotal in human carcinogenesis and in DNA synthesis induction, cell death modulation, cellular life span extension, genomic instability, cytoskeleton changes, alteration of the cellular polarity, as well as induction of pro-angiogenic factors and of the EMT, a process which is important in invasion and metastasis $(70,71)$.
E6 and E7 enhance cell proliferation of the infected cells on the basal layer of the epithelial surface (80). Numerous studies have shown that the Wnt-pathway is activated in virally-associated cancers, including cancer induced by herpes and hepatitis viruses (72). Various viral oncoproteins have been shown to activate Wnt-signaling through stabilization of transcriptionally-active $\beta$-catenin by different mechanisms (72).

Rampias et al demonstrated the activated Wnt-signaling pathway and the up-regulated cytoplasmic pool of $\beta$-catenin in HPV-positive oropharyngeal cancer compared to nonHPV-associated HNSCC and further suggested that nuclear accumulation of catenin is a direct consequence of E6 and E7 oncogene expression in HPV 16-positive oropharyngeal and cervical cancer cell lines (73). The cytosolic accumulation was not contributed to a $\beta$-catenin relocalization from the cell membrane. It was hypothesized that E6/E7 alters the Siah-1mediated degradation of $\beta$-catenin. Siah- 1 is a target gene of p53. Restoration of p53 leads to increased degradation of cytoplasmic $\beta$-catenin (73).

The data provide evidence that HPV infection of squamous epithelial surfaces is associated with a strong nuclear translocation of transcriptionally active $\beta$-catenin and with activation of the Wnt-pathway and vice versa that repression of viral oncogenes like E6 and E7 leads to a down-regulation of nuclear catenin (73). Al Moustafa et al suggest that E6/E7 cooperate with ErbB-2, a member of the EGF receptor family of receptor tyrosine kinases, in head and neck carcinogenesis, at least in part, via the conversion of $\beta$-catenin from a cell adhesion to a nuclear compartment molecule, that acts as a potential transcriptional regulator (74). The dysregulated activation of ErbB-2 provokes a dissociation of the E-cadherin/ catenin complex by tyrosine phosphorylation of $\beta$-catenin. These studies provide evidence that the ErbB2 receptor cooperates with high risk HPV infections in human carcinogenesis including cervical, head and neck, breast and probably colorectal cancers and their metastases. Further data by Uren et al illustrate that viral E6 and E7 gene expression activates the canonical Wnt-pathway and therefore, high-risk HPV infection is per se sufficient to promote carcinogenesis (75).

The studies of Lichtig et al provide support for an augmented Wnt/ $\beta$-catenin oncogenic signaling pathway in HPV-associated SCC (76). This stimulatory effect seemed to be independent of inhibiting $\mathrm{p} 53$ and GSK-3 $\beta$ or APC. The underlying mechanism is yet unknown. The purpose of this study was to investigate the effect of tyrosine kinase inhibitory therapy with imatinib on HPV-16-associated SCC compared to non-HPV-induced HNSCC and its impact on the expression pattern of $\beta$-catenin and c-kit. We demonstrated that the $\beta$-catenin expression levels, in HNSCC as well as in CERV196 tumor cells, showed a reliable trend towards a significantly decreased expression under imatinib treatment for an extended incubation period, whereas increased concentrations of the treatments had no significant influence. In contrast to previously reported data, we observed a lower intrinsic expression levels of secreted $\beta$-catenin in negative controls of CERV196 cells compared to non-HPV-associated tumor cell lines. The imatinib-induced $\beta$-catenin reduction appeared with delay; whether this effect is contributed to viral oncogene E6/E7-augmented Wnt-activation or less vulnerability of HPV-16-associated SCC remains to be discussed. Apparently there is a time lag until the imatinib-induced PTK 
inhibition takes effect in reducing $\beta$-catenin in CERV196. The reason why the p16-positive squamous carcinoma cell line is less vulnerable towards PTK therapy, particularly after short incubation periods (until $72 \mathrm{~h}$ ) remains unclear. Increased expression levels of cytosolic and nuclear $\beta$-catenin have been found to be associated with worse outcome in a variety of malignancies including ovarian, non-small cell lung cancer, melanoma, cervical, breast, bladder and nasopharyngeal carcinoma. To the contrary, cytoplasmic accumulation and nuclear translocation of $\beta$-catenin has been correlated with poor outcome in hepatocellular, esophageal, hepatoblastoma, thyroid, breast and head and neck carcinomas (77). The reduction in the level of mural expression of $\beta$-catenin has been associated with loss of differentiation in laryngeal carcinomas (78). In laryngeal cancer, the percentage of tumors showing increased cytoplasmic reactivity for $\beta$-catenin increased with histological dedifferentiation (79). Increased cytoplasmic $\beta$-catenin is to be a pivotal feature of malignancy. Pukkila et al have shown that the nuclear $\beta$-catenin expression is an independent predictor of a shorter overall survival in HNSCC (77). The elucidated suppression of cytosolic $\beta$-catenin by imatinib, irrespective of the HPV status, may stabilize unconstrained proliferation and reduce the invasive potential of neoplastic cells.

Ligands and receptors are usually expressed in different cell types. The stem cell factor (SCF) is the pleiotropic ligand for the tyrosine kinase receptor, c-kit. It has been reported that the binding of SCF to c-kit promotes cell proliferation, differentiation and recruitment of progenitor cells. Several cell types have been shown to co-express SCF and c-kit, as for example human mast cells (80). However, the majority of studies exploring the expression of the c-kit receptor and its ligand indicate a possible association of their co-expression with neoplastic transformation, primarily in epithelial tissues (46-48,81). Furthermore, ectopic expression of c-kit in NIH 3T3 fibroblasts induces tumorigenesis (82). Wang-Rodriguez et al observed the frequent expression of c-kit in HNSCC, indicating that these membranous proteins could be relevant targets of small molecule inhibitors (58). Furthermore, the data suggest that imatinib does not alter the expression level of c-kit, but rather acts by way of inhibiting PTK phosphorylation and activation. In contrast we could demonstrate that imatinib significantly alters the expression level of c-kit in HNSCC- and HPV-associated SCC, but in a more subtle manner.

The marked effect of selective tyrosine kinase inhibitory therapy in suppressing ectopic c-kit and $\beta$-catenin expression as warrantors of unconstrained cell proliferation and disrupted cell-cell interaction as well as cell differentiation in p16-positive and -negative tumor cell lines, justifies an eventual extension of this study to an animal model. Further studies are planned to investigate this observance in HPV-positive HNSCC in vitro. The implementation of a selective molecular therapy in established chemotherapeutic regimes may enhance the efficacy of platinum-based chemotherapy without increasing toxicity and could thereby improve clinical outcome in HNSCC, irrespective of HPV status.

\section{Acknowledgements}

The authors would like to thank Petra Prohaska for her excellent technical assistance, Dr Chr. Weiss for her great assistance in statistical analysis, and Novartis Pharma for kindly providing imatinib.

\section{References}

1. Parkin DM, Bray F, Ferlay J, et al: Global cancer statistics, 2002. J Clin Cancer 55: 74-108, 2002.

2. IARC (International Agency for Research on Cancer): Globocan. www.dep.iarc.fr, 2002.

3. Ries LAG, Eisner MP, Kosary CL, et al: SEER Cancer Statistics Review 1975-2002. National Cancer Institute, Bethesda MD, http:// seer.cancer.gov/csr/1975_2002/, based on November 2004 SEER data submission, posted to the SEER web site 2005.

4. Romanitan M, Näsman A, Ramqvist T, et al: Human papillomavirus frequency in oral and oropharyngeal cancer in Greece. Anticancer Res 28: 2077-2080, 2008.

5. Chaturvedi AK, Engels EA, Anderson WF and Gillison ML: Incidence trends for human papillomavirus-related and -unrelated oral squamous cell carcinomas in the United States. J Clin Oncol 26: 612-619, 2008.

6. Gillison ML, D'Souza G, Westra W, et al: Distinct risk factor profiles for human papillomavirus type 16-positive and human papillomavirus type 16-negative head and neck cancers. J Natl Cancer Inst 100: 407-420, 2008.

7. Shiboski CH, Schmidt BL and Jordan RC: Tongue and tonsil carcinoma: increasing trends in the U.S. population ages 20-44 years. Cancer 103: 1843-1849, 2005.

8. Näsman A, Attner P, Hammarstedt L, et al: Incidence of human papilloma virus (HPV) positive tonsillar carcinoma in Stockholm, Sweden: an epidemic of viral induced carcinoma? Int J Cancer 125: 362-366, 2009.

9. Dilianis T, Näsman A, Attner P, et al: Human papillomavirus in tonsillar cancer, an epidemic of viral carcinoma. 25th International Papillomavirus Conference and Clinical Workshop; Malmö, Sweden May 8-14, Abst O17.04, 2009.

10. Hansson BG, Rosenquist K, Antonsson A, et al: Strong association between infection with human papillomavirus and oral and oropharyngeal squamous cell carcinoma: a population-based case control study in southern Sweden. Acta Otolaryngol 125: 1337-1344, 2005.

11. Brandsma JL and Abramson AL: Association of papillomavirus with cancers of the head and neck. Arch Otolaryngol Head Neck Surg 115: 621-625, 1989.

12. Pyeon D, Lambert PF and Ahlquist P: Production of infectious human papillomavirus independently of viral replication and epithelial cell differentiation. Proc Natl Acad Sci USA 102: 9311-9316, 2005.

13. Wiest T, Schwarz E, Enders C, Flechtenmacher C and Bosch FX: Involvement of intact HPV16 E6/E7 gene expression in head and neck cancers with unaltered p53 status and perturbed $\mathrm{pRb}$ cell cycle control. Oncogene 21: 1510-1517, 2002.

14. Califano J, van der Reit P, Westra W, et al: Genetic progression model for head and neck cancer: implications for field cancerization. Cancer Res 56: 2488-2492, 1996.

15. Goodwin EC and DiMaio D: Repression of human papillomavirus oncogenes in HeLa cervical carcinoma cells causes the orderly reactivation of dormant tumor suppressor pathways. Proc. Natl Acad Sci USA 97: 12513-12518, 2000.

16. Hawley-Nelson P, Vousden KH, Hubbert NL, Lowy DR and Schiller JT: HPV16 E6 and E7 proteins cooperate to immortalize human foreskin keratinocytes. EMBO J 8: 3905-3910, 1989.

17. Sidransky D: Molecular genetics of head and neck cancer. Curr Opin Oncol 7: 229-233, 1995

18. McDougall JK: Immortalization and transformation of human cells by human papillomavirus. Curr Top Microbiol Immunol 186: $101-119,1994$.

19. Narisawa-Saito M and Kiyono T: Basic mechanisms of high-risk human papillomavirus-induced carcinogenesis: roles of E6 and E7 proteins. Cancer Sci 98: 1505-1511, 2007.

20. Tang X, Zhang Q, Nishitani J, et al: Overexpression of human papillomavirus type 16 oncoproteins enhances hypoxia-inducible factor 1 alpha protein accumulation and vascular endothelial growth factor expression in human cervical carcinoma cells. Clin Cancer Res 13: 2568-2576, 2007.

21. Hunter T: Oncoprotein networks. Cell 88: 333-346, 1997.

22. Vogel A, Rodriguez C, Warnken W and Izpisua Belmonte JC: Dorsal cell fate specified by chick Lmx1 during vertebrate limb development. Nature 378: 716-720, 1995. 
23. Polakis P: Wnt signaling and cancer. Genes Dev 14: 1837-1851, 2000.

24. Lustig B and Behrens J: The Wnt signaling pathway and its role in tumor development. J Cancer Res Clin Oncol 129: 199-221, 2003.

25. Clevers $\mathrm{H}: \mathrm{Wnt} / \beta$-catenin signaling in development and disease. Cell 127: 469-480, 2006.

26. Kikuchi A: Tumor formation by genetic mutations in the components of the Wnt signaling pathway. Cancer Sci 94: 225-229, 2003.

27. Giles RH, van Es JH and Clevers H: Caught up in a Wnt storm: Wnt signaling in cancer. Biochim Biophys Acta 1653: 1-24, 2003

28. Sauter A, Soulsby H, Hormann K and Naim R: Sulindac sulfone induces a decrease of $\beta$-catenin in HNSCC. Anticancer Res 30 : 339-343, 2010

29. Aberle H, Schwartz H and Kemler R: Cadherin-catenin complex: protein interactions and their implications for cadherin function. J Cell Biochem 61: 514-523, 1996.

30. Huber MA, Kraut N and Beug H: Molecular requirements for epithelial-mesenchymal transition during tumor progression. Curr Opin Cell Biol 17: 548-558, 2005.

31. Thiery JP: Epithelial-mesenchymal transitions in tumor progression. Nat Rev Cancer 2: 442-454, 2002.

32. Leethanakul C, Patel V, Gillespie J, et al: Distinct pattern of expression of differentiation and growth-related genes in squamous cell carcinomas of the head and neck revealed by the use of laser capture microdissection and cDNA arrays. Oncogene 19: 3220-3224, 2000.

33. Rhee CS, Sen M, Lu D, et al: Wnt and frizzled receptors as potential targets for immunotherapy in head and neck squamous cell carcinomas. Oncogene 21: 6598-6605, 2002.

34. Serrano M, Hannon GJ and Beach D: A new regulatory motif in cell-cycle control causing specific inhibition of cyclin D/CDK4. Nature 366: 704-707, 1993.

35. Yang F, Zeng Q, Yu G, Li S and Wang CY: Wnt $/ \beta$-catenin signaling inhibits death receptor-mediated apoptosis and promotes invasive growth of HNSCC. Cell Signal 18: 679-687, 2006.

36. Nelson WJ and Nusse R: Convergence of Wnt, $\beta$-catenin, and cadherin pathways. Science 303: 1483-1487, 2004.

37. Hart MJ, de los Santos R, Albert IN, Rubinfeld B and Polakis P: Downregulation of $\beta$-catenin by human Axin and its association with the APC tumor suppressor, $\beta$-catenin and GSK-3 $\beta$. Curr Biol 8: 573-581, 1998.

38. Sakanaka C, Weiss JB and Williams LT: Bridging of $\beta$-catenin and glycogen synthase kinase-3 $\beta$ by axin and inhibition of $\beta$-catenin-mediated transcription. Proc Natl Acad Sci USA 95 3020-3023, 1998.

39. Hajra KM and Fearon ER: Cadherin and catenin alterations in human cancer. Genes Chromosomes Cancer 34: 255-268, 2002.

40. Cantley LC, Auger KR, Carpenter C, et al: Oncogenes and signal transduction. Cell 64: 281-302, 1991.

41. Blume-Jensen $P$ and Hunter T: Oncogenic kinase signaling Nature 411: 355-365, 2001.

42. Williams DE, Eisenman J, Baird A, Rauch C, Van Ness K, March CJ, Park LS, et al: Identification of a ligand for the c-kit proto-oncogene. Cell 63: 167-174, 1990.

43. Trieselmann NZ, Soboloff J and Berger SA: Mast cells stimulated by membrane-bound, but not soluble, steel factor are dependent on phospholipase C activation. Cell Mol Life Sci 60: 759-766, 2003.

44. Caruana G, Cambareri AC and Ashman LK: Isoforms of c-KIT differ in activation of signaling pathways and transformation of NIH3T3 fibroblasts. Oncogene 18: 5573-5581, 1999.

45. Broudy VC: Stem cell factor and hematopoiesis. Blood 90 $1345-1364,1997$

46. Welker P, Schadendorf D, Artuc M, Grabbe J and Henz BM Expression of SCF splice variants in human melanocytes and melanoma cell lines: potential prognostic implications. Br J Cancer 82: 1453-1458, 2000.

47. Zheng R, Klang K, Gorin NC and Small D: Lack of KIT or FMS internal tandem duplications but co-expression with ligands in AML. Leuk Res 28: 121-126, 2004.

48. Hines SJ, Organ C, Kornstein MJ and Krystal GW: Coexpression of the c-kit and stem cell factor genes in breast carcinomas. Cell Growth Differ 6: 769-779, 1995.

49. Ongkeko WM, Altuna X, Weisman RA and Wang-Rodriguez J: Expression of protein tyrosine kinases in head and neck squamous cell carcinomas. Am J Clin Pathol 124: 71-76, 2005.

50. Bruce IA, Slevin NJ, Homer JJ, McGrown AT and Ward TH: Synergistic effects of imatinib in combination with chemotherapeutic drugs in head and neck cancer. Anticancer Drugs 16 719-726, 2005
51. Druker BJ and Lydon NB: Lessons learned from the development of an abl tyrosine-kinase inhibitor for chronic myelogenous leukemia. J Clin Invest 105: 3-7, 2000.

52. O'Dwyer ME, Mauro MJ and Druker BJ: STI571 as a targeted therapy for CML. Cancer Invest 21: 429-438, 2003.

53. Roskoski R Jr: STI-571: an anticancer protein-tyrosine kinase inhibitor. Biochem Biophys Res Commun 309: 709-717, 2003.

54. Shore SK, Bogart SL and Reddy EP: Activation of murine c-Abl protooncogene: effect of a point mutation on oncogenic activation. Proc Natl Acad Sci USA 87: 6502-6506, 1990.

55. Demetri GD, von Mehren M, Blanke CD, et al: Efficacy and safety of imatinib mesylate in advanced gastrointestinal stromal tumors. N Engl J Med 347: 472-480, 2002.

56. Croom KF and Perry CM: Imatinib mesylate: in the treatment of gastrointestinal stromal tumors. Drugs 63: 513-522, 2003.

57. Vlahovic G, Ponce AM, Rabbani Z, et al: Treatment with imatinib improves drug delivery and efficacy in NSCLC xenografts. Br J Cancer 97: 735-740, 2007.

58. Wang-Rodriguez J, Lopez JP and Altuna X: STI-571 (Gleevec) potentiates the effect of cisplatin in inhibiting the proliferation of head and neck squamous cell carcinoma in vitro. Laryngoscope 116: 1409-1416, 2006.

59. Schultz JD, Rotunno S, Sauter A, et al: Synergistic effects of imatinib and carboplatin on VEGF, PDGF and PDGF-R $\alpha / \beta$ expression in squamous cell carcinoma of the head and neck in vitro. Int J Oncol 38: 1001-1012, 2011.

60. Adler PN and Lee H: Frizzled signaling and cell-cell interactions in planar polarity. Curr Opin Cell Biol 13: 635-640, 2001.

61. Saldanha J, Singh J and Mahadevan D: Identification of a Frizzled-like cysteine rich domain in the extracellular region of developmental receptor tyrosine kinases. Protein Sci 7: 1632, 1998.

62. Gillison ML: Human papillomavirus-associated head and neck cancer is a distinct epidemiologic, clinical, and molecular entity. Semin Oncol 31: 744-754, 2004.

63. D'Souza G, Kreimer AR, Viscidi R, et al: Case-control study of human papillomavirus and oropharyngeal cancer. New Engl J Med 356: 1944-1956, 2007.

64. Mork J, Lie AK, Glattre E, et al: Human papillomavirus infection as a risk factor for squamous-cell carcinoma of the head and neck. New Engl J Med 344: 1125-1131, 2001.

65. Lindquist D, Romanitan M, Hammarstedt L, et al: Human papillomavirus is a favourable prognostic factor in tonsillar cancer and its oncogenic role is supported by the expression of E6 and E7. Mol Oncol 1: 350-355, 2007.

66. Lindel K, Beer KT, Laissue J, Greiner RH and Aebersold DM: Human papillomavirus positive squamous cell carcinoma of the oropharynx: a radiosensitive subgroup of head and neck carcinoma. Cancer 92: 805-813, 2001.

67. Bristow RG, Benchimol S and Hill RP: The p53 gene as a modifier of intrinsic radiosensitivity: implications for radiotherapy. Radiother Oncol 40: 197-223, 1996.

68. Dahm-Daphi J: p53: biology and role for cellular radiosensitivity. Strahlenther Onkol 176: 278-285, 2000.

69. Nelson AR, Fingleton BM, Rothenberg ML and Matrisian LM: Matrix metalloproteinases: biologic activity and clinical implications. J Clin Oncol 18: 1135-1149, 2000.

70. Hellner K and Münger K: Human papillomaviruses as therapeutic targets in human cancer. J Clin Oncol 29: 1785-1794, 2011.

71. Hellner K, Mar J, Fang F, et al: HPV16 E7 oncogene expression in normal human epithelial cells causes molecular changes indicative of an epithelial to mesenchymal transition. Virology 391: 57-63, 2009.

72. Hayward SD, Liu, J and Fujimuro M: Notch and Wnt signaling: mimicry and manipulation by gamma herpesviruses. Sci STKE 2006: re4, 2006.

73. Rampias T, Boutati E, Pectasides E, et al: Activation of Wnt signaling pathway by human papillomavirus E6 and E7 oncogenes in HPV16-positive oropharyngeal squamous carcinoma cells. Mol Cancer Res 8: 433-443, 2010.

74. Al Moustafa AE, Foulkes WD, Benlimame N, et al: E6/ E7 proteins of HPV type 16 and ErbB-2 cooperate to induce neoplastic transformation of primary normal oral epithelial cells. Oncogene 23: 350-358, 2004.

75. Uren A, Fallen S, Yuan H, et al: Activation of the canonical Wn pathway during genital keratinocyte transformation: a model for cervical cancer progression. Cancer Res 65: 6199-6206, 2005.

76. Lichtig H, Gilboa DA, Jackman A, Gonen P, Levav-Cohen Y, Haupt Y and Sherman L: HPV16 E6 augments Wnt signaling in an E6AP-dependent manner. Virology 396: 47-58, 2010. 
77. Pukkila MJ, Virtaniemi JA, Kumpulainen EJ, et al: Nuclear $\beta$-catenin expression is related to unfavourable outcome in oropharyngeal and hypopharyngeal squamous cell carcinoma. J Clin Pathol 54: 42-47, 2001.

78. Lopez-Gonzalez JS, Cristerna-Sanchez L, Vazquez-Manriquez ME Jimenez-Orci G, Aguilar-Cazares D: Localization and level of expression of beta-catenin in human laryngeal squamous cell carcinoma. Otolaryngol Head Neck Surg 130: 89-93, 2004.

79. Hirvikoski P, Kumpulainen EJ, Virtaniemi JA, Helin HJ, Rantala I, Johansson RT, Juhola M and Kosma VM: Cytoplasmic accumulation of alpha-catenin is associated with aggressive features in laryngeal squamous-cell carcinoma. Int J Cancer 79: $546-550,1998$
80. Welker P, Grabbe J, Gibbs B Zuberbier T and Henz BM: Human mast cells produce and differentially express both soluble and membrane-bound stem cell factor. Scand J Immunol 49: 495-500, 1999.

81. Doneda L, Klinger FG, Larizza L and de Felici M: KL/KIT co-expression in mouse fetal oocytes. Int J Dev Biol 46: 1015-1021, 2002.

82. Caruana G, Cambareri AC, Gonda TJ and Ashman LK Transformation of NIH3T3 fibroblasts by the c-Kit receptor tyrosine kinase: effect of receptor density and ligand-requirement. Oncogene 16: 179-190, 1998. 